\title{
Risk Factors Associated with Juvenile Idiopathic Arthritis: Exposure to Cigarette Smoke and Air Pollution from Pregnancy to Disease Diagnosis
}

\author{
Camila Maria Paiva França, Adriana Maluf Elias Sallum, Alfésio Luis Ferreira Braga, \\ Fernando Louzada Strufaldi, Clovis Artur Almeida Silva, and Sylvia Costa Lima Farhat
}

\begin{abstract}
Objective. To evaluate exposure to environmental factors inhaled during pregnancy and after birth until juvenile idiopathic arthritis (JIA) diagnosis among residents of a large city.

Methods. This is an exploratory case-control study that consists of 66 patients with JIA and 124 healthy controls matched by age and sex, living in the São Paulo, Brazil, metropolitan area until JIA diagnosis, and whose mothers had resided in this region during pregnancy. A structured and reliable questionnaire ( $\kappa$ index for test-retest was 0.80 ) assessed demographic data, gestational and perinatal-related factors, and exposure to inhalable environmental elements during pregnancy and after birth (occupational exposure to inhalable particles and/or volatile vapor, exposure to cigarette smoke, and the presence of industrial activities or gas stations near the home, work, daycare, or school). Tropospheric pollutants included particulate matter $\left(\mathrm{PM}_{10}\right)$, sulfur dioxide $\left(\mathrm{SO}_{2}\right)$, nitrogen dioxide $\left(\mathrm{NO}_{2}\right)$, ozone $\left(\mathrm{O}_{3}\right)$, and carbon monoxide (CO).

Results. During pregnancy, intrauterine cigarette smoke exposure (OR 3.43, 95\% CI 1.45-8.12, $\mathrm{p}=$ 0.005) and maternal occupational exposure (OR 13.69, 95\% CI 4.4-42.3, p < 0.001) were significant independent risk factors for JIA diagnosis. In contrast, maternal employment (OR $0.06,95 \%$ CI $0.02-0.2, \mathrm{p}<0.001)$ and ideal maternal weight gain (OR $0.36,95 \%$ CI $0.2-0.8, \mathrm{p}=0.017)$ presented negative associations. Secondhand smoke exposure from birth to JIA diagnosis (OR 3.6, 95\% CI $1.8-7.3, \mathrm{p}<0.001)$ and exposure to $\mathrm{O}_{3}$ during the second year of life (OR 2.76, 95\% CI 1.20-6.37, $\mathrm{p}=0.017$ ) were independent and significant risk factors for the pathogenesis of JIA.

Conclusion. In our study, cigarette smoke exposure (intrauterine and after birth), exposure to $\mathrm{O}_{3}$ in the second year of life, and maternal occupational exposure were identified as potential risk factors for JIA, warranting further study. (First Release November 15 2017; J Rheumatol 2018;45:248-56; doi:10.3899/jrheum.161500)
\end{abstract}

Key Indexing Terms:

JUVENILE IDIOPATHIC ARTHRITIS AIR POLLUTION

Exposure to fine/ultrafine particles and other pollutants has been associated with disturbances in systemic inflammation and immune responses $1,2,3,4$. Ambient (outdoor) and household (indoor) pollutants are both important environ-

\section{ENVIRONMENTAL FACTOR SMOKING MATERNAL OCCUPATIONAL EXPOSURE}

mental risks to human health ${ }^{5}$. Indoor pollutants include cigarette smoke, domestic dust, and volatile organic compounds ${ }^{6,7}$. The outdoor pollutants monitored by environmental agencies are sulfur dioxide $\left(\mathrm{SO}_{2}\right)$, nitrogen dioxide
From the Environmental Epidemiology Study Group, Laboratory of Experimental Air Pollution, and the Division of Rheumatology, Faculdade de Medicina da Universidade de São Paulo; Pediatric Rheumatology Unit, and Emergency Department, Children's Institute, Faculdade de Medicina, Universidade de São Paulo, São Paulo; Environmental Exposure and Risk Assessment Group, Collective Health Post-graduation Program, Universidade Católica de Santos, Santos, Brazil.

Supported by grants from Conselho Nacional de Desenvolvimento Científico e Tecnológico (CNPq 472155/2012-1 to CAS and 302724/ 2011-7 to CAS), Federico Foundation (to CAS), and by Núcleo de Apoio à Pesquisa "Saúde da Criança e do Adolescente" da USP (NAP-CriAd) to CAS.

C.M. França, MD, PhD, Pediatric Rheumatology Unit, Children's Institute, Faculdade de Medicina, Universidade de São Paulo; A.M. Sallum, MD, PhD, Pediatric Rheumatology Unit, Children's Institute, Faculdade de Medicina, Universidade de São Paulo; A.L. Braga, MD, PhD, Environmental Epidemiology Study Group, Laboratory of Experimental Air Pollution, Faculdade de Medicina da Universidade de
São Paulo, and Environmental Exposure and Risk Assessment Group, Collective Health Post-graduation Program, Universidade Católica de Santos; F.L. Strufaldi, MB, Environmental Epidemiology Study Group, Laboratory of Experimental Air Pollution, Faculdade de Medicina da Universidade de São Paulo; C.A. Silva, MD, PhD, Pediatric

Rheumatology Unit, Children's Institute, Faculdade de Medicina, Universidade de São Paulo, and Division of Rheumatology, Faculdade de Medicina, Universidade de São Paulo; S.C. Farhat, $M D, P h D$, Environmental Epidemiology Study Group, Laboratory of Experimental Air Pollution, Faculdade de Medicina da Universidade de São Paulo, and Emergency Department, Children's Institute, Faculdade de Medicina, Universidade de São Paulo.

Address correspondence to Dr. S.C. Farhat, Faculdade de Medicina da Universidade de São Paulo, Núcleo de Estudos em Epidemiologia Ambiental, Laboratório Atmosférica Experimental, Avenida Dr. Arnaldo, 455, $1^{\circ}$ andar, sala 1304, São Paulo, 01246-903, Brazil. E-mail:sylvia.farhat@gmail.com

Accepted for publication September 8, 2017. 
$\left(\mathrm{NO}_{2}\right)$, carbon monoxide $(\mathrm{CO})$, ozone $\left(\mathrm{O}_{3}\right)$, and particulate matter $\left(\mathrm{PM}_{10}\right)^{5}$.

Fine and ultrafine inhalable particles are those with diameters smaller than $2.5 \mu \mathrm{m}$ and $0.1 \mu \mathrm{m}$, respectively. These particles consist of solid and liquid parts, in which several compounds are adsorbed. Exposure to these inhalable particles can trigger pulmonary oxidative stress and inflammation $^{8}$, and may lead to systemic inflammation. Exposure to air pollutants may increase inflammatory cytokines levels in adults and children, such as interleukin $1 \beta$, interleukin 6 and tumor necrosis factor- $\alpha^{9,10}$. However, few studies have evaluated an association between exposure to outdoor pollutants and rheumatic diseases in adults $2,3,11,12,13,14$ or children ${ }^{4,15,16,17,18,19}$.

Prenatal exposure to environmental factors has been associated with several childhood diseases. In fact, fetal exposure to toxins has been linked to early programming for childhood illnesses ${ }^{17,20,21}$. However, studies on pediatric rheumatic diseases involving exposure to inhalable pollutants during pregnancy, and from birth to disease diagnosis, are still rare ${ }^{16,17,18,19,22,23,24}$.

Juvenile idiopathic arthritis (JIA) is a heterogeneous group of autoimmune diseases and it is the main cause of chronic arthritis in children and adolescents ${ }^{25}$. Some studies have associated environmental factors with JIA onset or diagnosis $16,18,22,23,24$. However, to our knowledge, the simultaneous evaluation of exposure to outdoor and indoor pollutants during pregnancy and from birth to JIA diagnosis has not yet been performed. The aim of our study was to analyze exposure to inhaled environmental factors both during pregnancy, and from birth to JIA diagnosis.

\section{MATERIALS AND METHODS}

This is an exploratory case-control study. From January 2013 to December 2014, the Pediatric Rheumatology Unit of the Children's Institute, Faculdade de Medicina da Universidade de São Paulo, Brazil, followed up on 172 patients with JIA classified according to the International League Against Rheumatism (ILAR) criteria ${ }^{25}$. Of these patients with JIA, 66 fulfilled the inclusion criteria for our study: they were residents of the São Paulo metropolitan area up to JIA diagnosis whose mothers had resided in this region at least 1 year before pregnancy, as well as during pregnancy. Patients with other pediatric chronic diseases and with incomplete information regarding pregnancy were excluded.

The control group was composed of 124 healthy age- and sex-matched children and adolescents who did not have any chronic inflammatory diseases. They were recruited from the primary care clinic after routine checkups, and fulfilled the same inclusion criteria as patients with JIA. Socioeconomic status was classified by the Brazilian Association of Market Research Institutions ${ }^{26}$. The Ethics Committee of our University Hospital approved our study (registration number 0095/09), and written informed consent was signed by the parent or guardian of the child. If age-appropriate, consent was obtained from the participating child.

Structured questionnaire to assess inhaled environmental factors. The data were obtained from patients with JIA and healthy control mothers by means of a structured questionnaire. A questionnaire that had been previously used by Guimarães, et $a l^{27}$ and Orione, et $a l^{17}$ was modified to include the following variables: (1) sociodemographic characteristics (socioeconomic status was classified by the Brazilian Association of Market Research
Institutions ${ }^{26}$ and took into account the educational level of the head of the family and the family's purchasing power); (2) JIA and control mothers' addresses during pregnancy (all addresses were evaluated, including relocations); (3) JIA and control mothers' occupations during pregnancy, including mother's occupation, commute time from home to workplace, and occupational exposure to specific pollutants, such as inhalable particulate matter (demolition, school chalk, sewing, construction, and quarry dust) and/or volatile vapor (paints, varnish, gasoline vapor, and other volatile substances); (4) gestational and perinatal-related factors, such as weight gain during pregnancy, gestational age, birth weight, and alcohol consumption during pregnancy ${ }^{28}$; (5) presence of stationary environmental sources (gas stations, factories, and quarries) within a radius of up to 500 meters from the residence, workplace, daycare, or school during JIA and control pregnancies, from birth to JIA diagnosis in the JIA group, and from birth to mean age at JIA diagnosis (6 yrs) in the control group; and (6) smoking by household residents during pregnancy and after birth for a 6 -year period. In most cases, the period between birth and JIA diagnosis was 6 years. Therefore, a 6-year period was adopted to explore exposure after birth.

From April to June 2014, a pilot study was performed involving 21 consecutive mothers. The subjects were also retested 5 to 10 days after the first questionnaire to ensure their understanding of the questions and to assess applicability and reliability of the questionnaire. Of note, these 21 mothers were included in the final analysis. After 5 to 10 months, a new evaluation with the same questions as in the test-retest was performed to verify the consistency of the answers over a longer interval.

Tropospheric pollutants and weather data. The São Paulo State Environmental Agency (CETESB) ${ }^{29}$ provided daily concentrations of $\mathrm{PM}_{10}(24-\mathrm{h}$ average), $\mathrm{SO}_{2}$ (24-h average), $\mathrm{NO}_{2}$ (the highest hourly average), $\mathrm{O}_{3}$ (the highest hourly average), and $\mathrm{CO}$ (the highest 8 -h moving average) from 22 automated pollution-monitoring stations in different parts of the São Paulo metropolitan area. The average pollutant levels measured at each station were adopted as an exposure status throughout the city because air pollutant levels recorded in each station were highly correlated.

The average concentration of each pollutant was calculated throughout the gestational period and from birth to JIA diagnosis in the JIA group, and from birth to the mean age of JIA diagnosis ( 6 yrs) in the control group. No patient with JIA and healthy control had the same birth date.

Statistical analysis. Continuous variables [mean $\pm \mathrm{SD}$ or median (IQR)] and categorical variables (\%) for patients with JIA and healthy control groups were included in descriptive analyses. Data were compared by Student $t$ tests or Mann-Whitney U tests for continuous variables. Categorical variables were assessed by chi-square test or Fisher's exact test. The test-retest reliability of the questionnaire was verified using the $\kappa$ index.

According to the characteristics of exposure assessed by the questionnaire, 7 groups of independent variables were defined (similar to Orione, et $\left.a l^{17}\right)$ :

(1) Employment. Maternal employment and occupational exposure to either of the following inhalable agents (dichotomous): inhalable particulate matter and/or volatile vapor.

(2) Daycare/school attendance, from birth until JIA diagnosis (dichotomous). (3) Exposure to cigarette smoke. Exposure to cigarette smoke during pregnancy was evaluated using these dichotomous variables: maternal smoking; maternal secondhand smoke exposure (mother who did not smoke but was exposed to secondhand smoke); and intrauterine cigarette smoke exposure (smoking mother and/or mother exposed to secondhand smoke). After birth, exposure to cigarette smoke was evaluated using 2 dichotomous variables: secondhand smoke exposure (child or adolescent exposed to secondhand smoke after birth); and child or adolescent always exposed (intrauterine and secondhand smoke exposure after birth).

(4) Gestational and perinatal-related factors, such as weight gain during pregnancy $(<11.5 \mathrm{~kg}, 11.5-16 \mathrm{~kg} ;>16 \mathrm{~kg})^{32}$, prematurity, birth weight $(<2.5 \mathrm{~kg} ; 2.5-4.0 \mathrm{~kg} ;>4.0 \mathrm{~kg})$, and alcohol consumption during pregnancy ${ }^{30}$ (yes or no, dichotomous).

(5) Home, workplace, daycare, or school distance to stationary environ-

Personal non-commercial use only. The Journal of Rheumatology Copyright @ 2018 . All rights reserved. 
mental sources of inhalable pollutants $(<100,100-200$, and $200-500 \mathrm{~m})$ during pregnancy, and from birth to JIA diagnosis.

(6) Exposure to traffic based on commute time from home to work, or to daycare or school $(<30,30-60$, and $>60 \mathrm{~min})$, and 5 indicators of exposure to tropospheric pollutants in each pregnancy trimester and in each year from birth until JIA diagnosis.

(7) Seasonality: season in late pregnancy (categorized).

Average concentration of each tropospheric pollutant in pregnancy (first, second, and third trimesters) and for each year from birth to JIA diagnosis were categorized into tertiles for each participant.

Variables with levels $<20 \%$ significance in a univariate model were used in multilevel models. We adopted a multilevel logistic regression model based on 7 groups of independent variables to identify variables for the final multiple model.

Independent variables that presented a significance level $<5 \%$ were used in the final multiple model. Regression model results were presented as OR and $95 \% \mathrm{CI}$. In all the statistical tests, significance was set at $5 \%(\mathrm{p}<0.05)$. The IBM-SPSS-20 program was used to perform statistical analyses.

\section{RESULTS}

The $\kappa$ index for test-retest was 0.80 , demonstrating an excellent reliability for mothers' responses.

The current age was similar between patients with JIA and healthy controls ( $10.8 \pm 3.9$ vs $11.2 \pm 4.3$ yrs $)$. Similarly, the frequency of women $(59.1 \%$ vs $57.3 \%$ ) between patients with JIA and healthy controls did not differ. Mean ages at first symptoms and at JIA diagnosis were $5.7 \pm 3.9$ years and 6.6 \pm 3.8 years, respectively. The 66 patients with JIA were classified according to ILAR criteria: $23(34.8 \%)$ were classified as rheumatoid factor (RF)-negative polyarthritis, $4(6 \%)$ as RF-positive polyarticular JIA, $20(30 \%)$ as oligoarticular, $17(26 \%)$ as systemic, and $2(3 \%)$ as other categories (1 psoriatic arthritis and 1 undifferentiated subtype). Anticitrullinated protein antibody was evaluated in 9 patients (13.6\%) and it was positive in only 1 case. There were 5 JIA patients who had uveitis prior to joining the study, 2 with oligoarticular JIA, 1 with RF-negative polyarthritis, 1 with systemic JIA, and 1 with psoriatic arthritis.

Table 1 presents gestational, perinatal-related and environmental factors in patients with JIA and healthy controls. The frequency of being in the lower-middle class was significantly higher in patients with JIA compared to healthy controls. The prevalence of intrauterine cigarette smoke exposure in patients with JIA and controls in the lower-middle class was similar to those in the upper classes ( $36.1 \%$ vs $25.6 \%$; $\mathrm{p}=0.17$ ). Likewise, the distance to fixed sources of inhalable pollutants was similar in both socioeconomic groups ( $44.3 \%$ vs $55.8 \%$; $\mathrm{p}=0.16$ ). No statistically significant differences in ideal maternal weight gain were observed between lower-middle and upper classes (45.9\% vs $44.2 \%)$. Regarding working, the number of upper-class mothers who worked during pregnancy was significantly higher $(75.2 \%$ vs $45.9 \%$; $p<0.001)$; however, maternal occupational exposure was more prevalent in the lower middle class than in the upper classes $(21.3 \%$ vs $8.5 \%$; $\mathrm{p}=0.02)$.

During pregnancy. Although a smaller number of mothers
Table 1. Gestational, perinatal-related, and environmental factors during gestation affecting patients with JIA and healthy controls. Values are n (\%) and mean $\pm \mathrm{SD}$

\begin{tabular}{|c|c|c|c|}
\hline \multirow{2}{*}{$\begin{array}{l}\text { Variables } \\
\text { During pregnancy }\end{array}$} & \multirow[t]{2}{*}{$\begin{array}{c}\text { JIA, } \\
\mathrm{n}=66\end{array}$} & \multicolumn{2}{|c|}{$\begin{array}{l}\text { Healthy Controls, } \mathrm{p} \\
\mathrm{n}=124\end{array}$} \\
\hline & & & \\
\hline Low/middle socioeconomic status & $31(47)$ & $30(24)$ & 0.002 \\
\hline \multicolumn{4}{|l|}{ Employment } \\
\hline Maternal employment & $26(39)$ & $99(80)$ & $<0.001$ \\
\hline Maternal occupational exposure & $15(23)$ & $10(8)$ & 0.006 \\
\hline \multicolumn{4}{|l|}{ Exposure to cigarette smoke } \\
\hline Maternal smoking & $10(15)$ & $3(2)$ & 0.002 \\
\hline Maternal secondhand smoke exposure & $28(42)$ & $25(20)$ & 0.002 \\
\hline Intrauterine cigarette smoke exposure & $32(48)$ & $26(21)$ & $<0.001$ \\
\hline$>20$ cigarettes/day & $15(48)^{\mathrm{a}}$ & $9(36)^{b}$ & 0.42 \\
\hline \multicolumn{4}{|l|}{ Gestational and perinatal-related factors } \\
\hline \multicolumn{4}{|l|}{ Maternal weight gain, ideal } \\
\hline Under ideal, $<11.5 \mathrm{~kg}$ & $37(56)$ & $48(39)$ & 0.032 \\
\hline Ideal, $11.5-16 \mathrm{~kg}$ & $16(24)$ & $60(48)$ & 0.002 \\
\hline Above ideal, $>16 \mathrm{~kg}$ & $13(20)$ & $16(13)$ & 0.290 \\
\hline Alcohol consumption & $2(3)$ & $1(1)$ & 0.280 \\
\hline Prematurity & $6(9)$ & $5(4)$ & 0.200 \\
\hline \multicolumn{4}{|l|}{ Birth weight } \\
\hline$<2.5 \mathrm{~kg}$ & $7(11)$ & $11(9)$ & 0.800 \\
\hline $2.5-4.0 \mathrm{~kg}$ & $57(86)$ & $110(90)$ & 0.650 \\
\hline$>4.0 \mathrm{~kg}$ & $2(3)$ & $2(2)$ & 0.610 \\
\hline \multicolumn{4}{|c|}{ Home/work distance to gas stations, factories, and quarries } \\
\hline$<100 \mathrm{~m}$ & $20(13)$ & $14(17)$ & 0.30 \\
\hline $100-200 \mathrm{~m}$ & $14(9)$ & $19(23)$ & 0.42 \\
\hline $200-500 \mathrm{~m}$ & $30(20)$ & $32(40)$ & 0.80 \\
\hline \multicolumn{4}{|l|}{ Traffic exposure } \\
\hline \multicolumn{4}{|l|}{ Commute time from home to work } \\
\hline$<30 \mathrm{~min}$ & $14(21)$ & $43(12)$ & 0.400 \\
\hline $30-60 \mathrm{~min}$ & $9(13)$ & $38(31)$ & 0.860 \\
\hline$>60 \mathrm{~min}$ & $3(5)$ & $19(15)$ & 0.400 \\
\hline \multicolumn{4}{|l|}{ Air pollutants } \\
\hline \multicolumn{4}{|c|}{$\mathrm{SO}_{2}$ in the 2 nd trimester of pregnancy, } \\
\hline$\mu \mathrm{g} / \mathrm{m}^{3}$ & $11.9 \pm 3.3$ & $13.9 \pm 5.3$ & 0.002 \\
\hline \multicolumn{4}{|l|}{ Season } \\
\hline \multicolumn{4}{|l|}{ Early pregnancy } \\
\hline Summer & $11(17)$ & $28(23)$ & 0.45 \\
\hline Autumn & $19(29)$ & $36(29)$ & 1.00 \\
\hline Winter & $15(23)$ & $33(27)$ & 0.60 \\
\hline Spring & $21(32)$ & $27(22)$ & 0.16 \\
\hline \multicolumn{4}{|l|}{ Late pregnancy } \\
\hline Summer & $19(29)$ & $19(29)$ & 1.00 \\
\hline Autumn & $14(21)$ & $14(21)$ & 0.480 \\
\hline Winter & $23(35)$ & $23(35)$ & 0.06 \\
\hline Spring & $10(15)$ & $10(15)$ & 0.20 \\
\hline After birth & & & \\
\hline Exposure to cigarette smoke & & & \\
\hline Secondhand smoke exposure & $33(50)$ & $23.4(29)$ & $<0.001$ \\
\hline Exposure to cigarette smoke, yrs & $3.5 \pm 4.5$ & $2.5 \pm 4.9$ & $<0.001$ \\
\hline Intrauterine and after-birth exposure & $27(41)$ & $21(17)$ & 0.14 \\
\hline Daycare/school attendance & $47(71)$ & $117(94)$ & $<0.001$ \\
\hline Daycare or school attendance, yrs & $4.0 \pm 4.9$ & $6.3 \pm 4.4$ & 0.01 \\
\hline Home/school distance to gas stations, fac & ctories, and & d quarries & \\
\hline$<100 \mathrm{~m}$ & $23(35)$ & $30(24)$ & 0.13 \\
\hline $100-200 \mathrm{~m}$ & $24(36)$ & $34(27)$ & 0.25 \\
\hline $200-500 \mathrm{~m}$ & $34(52)$ & $60(48)$ & 0.76 \\
\hline Traffic exposure & & & \\
\hline Commute time from home to work & & & \\
\hline$<30 \mathrm{~min}$ & $38(58)$ & $79(64)$ & 0.13 \\
\hline $30-60 \mathrm{~min}$ & $4(6)$ & $23(19)$ & 0.10 \\
\hline$>60 \mathrm{~min}$ & $6(9)$ & $14(11)$ & 1.0 \\
\hline Air pollutants & & & \\
\hline $\mathrm{O}_{3}$ exposure, 2nd yr of life, $\mu \mathrm{g} / \mathrm{m}^{3} 8$ & $86.03 \pm 7.3$ & $82.8 \pm 6.4$ & 0.04 \\
\hline
\end{tabular}

${ }^{a} \mathrm{n}=31 ;{ }^{b} \mathrm{n}=25$. JIA: juvenile idiopathic arthritis; $\mathrm{O}_{3}$ : ozone; $\mathrm{SO}_{2}:$ sulfur dioxide.

Personal non-commercial use only. The Journal of Rheumatology Copyright $\odot$ 2018. All rights reserved. 
with JIA worked during pregnancy compared to the number of healthy control mothers (Table 1), the average hours worked per day were similar in both groups. Further, occupational exposure during pregnancy among working mothers with JIA was significantly higher than that for the control working mothers (exposure to fine dust: $23.1 \%$ vs $3.0 \%$; $\mathrm{p}=0.003$, and exposure to volatile vapor: $34.6 \%$ vs $7.1 \%$; $\mathrm{p}=0.001)$. In the JIA group, mothers exposed to these substances were employed as teachers $(\mathrm{n}=2)$, seamstresses $(n=4)$, beauty salon workers $(n=2)$, copy machine operators $(\mathrm{n}=1)$, and cleaners $(\mathrm{n}=6)$; and in the control group, mothers worked as teachers $(\mathrm{n}=2)$, architects $(\mathrm{n}=1)$, cleaners $(n=6)$, and copy machine operators $(n=1)$.

Maternal smoking and exposure to secondhand smoke at home during pregnancy were significantly more prevalent in the JIA group than in the controls (Table 1). The number of mothers who were smoking 1 year prior to the pregnancy was higher among mothers of patients with JIA than among control mothers $(22.7 \%$ vs $6.5 \%$; $p=0.002)$.

Regarding gestational and perinatal-related factors, ideal weight gain was lower in the JIA group compared to the controls. There was no significant difference in terms of prematurity or alcohol consumption between the 2 groups.

Distance from home or work to factories or gas stations during pregnancy was similar for patients with JIA and healthy controls, as well as commute time from home to the workplace.

Table 2 shows the results of the univariate logistic regression models for the groups of independent variables related to pregnancy. An association with a significance level $<20 \%$ was observed between employment variables, exposure to tobacco, maternal weight gain, prematurity, and home/work distance to environmental sources of inhalable pollutants (gas stations, factories, and quarries). Regarding exposure to tropospheric pollutants during pregnancy, only $\mathrm{SO}_{2}$ in the second trimester was significantly associated with JIA diagnosis.

The results of the multilevel logistic regression approach are shown in Table 2. It was observed that maternal employment, occupational exposure, intrauterine cigarette smoke exposure, and ideal maternal weight gain remained significant, and these variables were included in the final model.

Table 2 also shows the results of a final multiple regression model, including the independent variable groups related to those who presented significance levels $<20 \%$ in a univariate model, and statistical significance in multilevel regression. Intrauterine cigarette smoke exposure and maternal occupational exposure remained independent and significant risk factors for JIA, while maternal employment and ideal maternal weight gain had negative associations.

From birth to JIA diagnosis. Table 1 presents data on exposure to cigarette smoke, daycare or school attendance, and environmental factors in patients with JIA and healthy controls.
Secondhand smoke exposure at home after birth was significantly more frequent in the JIA group than in the control group.

Table 3 depicts univariate logistic regression models for groups of independent variables related to the after-birth period. Regarding exposure to tropospheric pollutants by year, only $\mathrm{O}_{3}$ in the second year of life was associated with JIA diagnosis.

To define the best indicator of traffic, these variables were included in the multilevel logistic regression analysis: commute time from home to daycare/school and $\mathrm{O}_{3}$ in the second year of life (Table 3). In this approach, only $\mathrm{O}_{3}$ in the second year of life remained significant and was included in the final model, along with the following variables: low/middle socioeconomic status, secondhand smoking, and daycare/school attendance.

The results of the final multiple regression model are shown in Table 3 . Secondhand smoking and $\mathrm{O}_{3}$ in the second year of life remained independent and significant risk factors for JIA. However, a negative association between the risk of JIA and daycare/school attendance was observed.

Table 4 demonstrates the final analysis, including all significant variables of the final models in both periods (pregnancy, and from birth to JIA diagnosis) for all patients and JIA categories. We found that only exposure to $\mathrm{O}_{3}$ in the second year of life was a risk factor to disease onset in the systemic JIA group, whereas ideal maternal weight gain and maternal employment during pregnancy remained negatively associated with the risk of systemic JIA. For the other JIA categories (RF-negative polyarthritis and oligoarticular JIA), the results were similar to those analyses performed with the full group.

\section{DISCUSSION}

To our knowledge, ours is the first study to simultaneously analyze the association of outdoor and indoor pollution with JIA diagnosis from pregnancy to disease onset.

Our study has several strengths. It used a structured questionnaire, assessing responses regarding exposure to inhalable environmental pollutants from pregnancy to JIA diagnosis. Additionally, a high $\kappa$ index for test-retest observed herein indicated that the questionnaire remained consistent in its responses. In contrast to other studies $16,18,22,23,24$, we evaluated exposure to environmental factors other than cigarette smoke, during pregnancy and up to JIA diagnosis, as a risk factor for disease diagnosis after birth. Relevant issues related to the pregnancy and perinatal period, such as alcohol consumption, prematurity, maternal weight gain, and birth weight were recorded. We also explored maternal occupational exposure to inhalable pollutants and tropospheric pollutants, which were systematically evaluated by automated monitoring stations in São Paulo ${ }^{29}$.

The main limitation of our study was that the assessment of indoor pollution was based only on cigarette smoke. Other

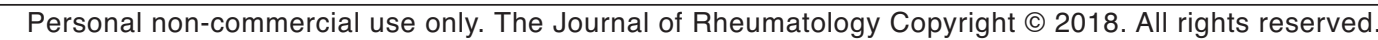


Table 2. Exposure to cigarette smoke and inhaled pollutants during gestation as risk factors for JIA in univariate, multilevel, and final multiple logistic regression models.

\begin{tabular}{|c|c|c|c|c|c|c|c|c|c|}
\hline \multirow[t]{2}{*}{ Variables during Pregnancy } & \multicolumn{3}{|c|}{$\begin{array}{l}\text { Univariate Logistic } \\
\text { Regression Model }\end{array}$} & \multicolumn{3}{|c|}{$\begin{array}{l}\text { Multilevel Logistic } \\
\text { Regression Model }\end{array}$} & \multicolumn{3}{|c|}{$\begin{array}{l}\text { Final Multiple Logistic } \\
\text { Regression Model }\end{array}$} \\
\hline & OR & $95 \% \mathrm{CI}$ & $\mathrm{p}$ & OR & $95 \% \mathrm{CI}$ & $\mathrm{p}$ & OR & $95 \% \mathrm{CI}$ & $\mathrm{p}$ \\
\hline \\
\hline Maternal employment & 0.16 & $0.1-0.3$ & $<0.001$ & 0.08 & $0.04-0.17$ & $<0.001$ & 0.06 & $0.02-0.2$ & $<0.001$ \\
\hline Maternal occupational exposure & 3.35 & $1.4-8.0$ & 0.006 & 12.1 & $4.4-33.5$ & $<0.001$ & 13.69 & $4.4-42.3$ & $<0.001$ \\
\hline Maternal secondhand smoke exposure & 2.92 & $1.5-5.6$ & 0.001 & 0.3 & $0.03-2.7$ & 0.30 & & & \\
\hline Intrauterine cigarette smoke exposure & 3.55 & $1.9-6.8$ & $<0.001$ & 11.5 & $1.3-16.7$ & 0.03 & 3.43 & $1.5-8.1$ & 0.005 \\
\hline$>20$ cigarettes/day & 1.67 & $0.6-4.9$ & 0.35 & & & & & & \\
\hline \multicolumn{10}{|l|}{ Gestational and perinatal-related factors } \\
\hline \multicolumn{10}{|l|}{ Maternal weight gain } \\
\hline Under ideal, $<11.5 \mathrm{~kg}$ & 2.02 & $1.1-3.7$ & 0.030 & 1.0 & $0.4-2.3$ & 0.90 & & & \\
\hline \multicolumn{10}{|l|}{ Birth weight } \\
\hline$<2.5 \mathrm{~kg}$ & 1.22 & $0.5-3.3$ & 0.700 & & & & & & \\
\hline $2.5-4.0 \mathrm{~kg}$ & 0.81 & $0.3-2.0$ & 0.640 & & & & & & \\
\hline$>4.0 \mathrm{~kg}$ & 1.91 & $0.3-13.9$ & 0.520 & & & & & & \\
\hline \multicolumn{10}{|c|}{ Home/work distance to gas stations, factories, and quarries } \\
\hline$<100 \mathrm{~m}$ & 0.83 & $0.4-1.9$ & 0.650 & & & & & & \\
\hline $100-200 \mathrm{~m}$ & 0.60 & $0.2-1.7$ & 0.350 & & & & & & \\
\hline $200-500 \mathrm{~m}$ & 0.26 & $0.1-0.6$ & 0.001 & & & & 1.47 & $0.6-3.5$ & 0.390 \\
\hline \multicolumn{10}{|l|}{ Traffic exposure } \\
\hline Commute time from home to work & 1.55 & $0.65-3.68$ & 0.32 & & & & & & \\
\hline$<30 \mathrm{~min}$ & 0.52 & $0.14-1.91$ & 0.33 & & & & & & \\
\hline $30-60 \mathrm{~min}$ & 0.86 & $0.35-2.13$ & 0.75 & & & & & & \\
\hline Autumn & 1.34 & $0.46-2.92$ & 0.51 & & & & & & \\
\hline Winter & 1.16 & $0.80-4.87$ & 0.76 & & & & & & \\
\hline Spring & 1.98 & $0.55-3.27$ & 0.21 & & & & & & \\
\hline \multicolumn{10}{|l|}{ Late pregnancy } \\
\hline Summer & - & - & - & & & & & & \\
\hline Autumn & 0.78 & $0.34-1.81$ & 0.51 & & & & & & \\
\hline Winter & 1.57 & $0.71-3.45$ & 0.76 & & & & & & \\
\hline Spring & 0.64 & $0.26-1.58$ & 0.21 & & & & & & \\
\hline
\end{tabular}

JIA: juvenile idiopathic arthritis; $\mathrm{SO}_{2}$ : sulfur dioxide.

elements, including fuels for household cooking and house dust, were not assessed. Referral bias may exist because we used a convenience sample from a tertiary hospital of patients residing in a metropolitan area. The Pediatric Rheumatology Service of our tertiary university hospital follows up on complex diseases, and many of our patients with JIA (41\%) had systemic onset ${ }^{31}$, which may be a referral bias. There are no nationwide Brazilian data on the prevalence of JIA and its categories. In 1 study, performed in a city in São Paulo state, the prevalence of JIA was reported to be $0.34 / 1000$ children aged 6 to 12 years, a value within the range of reported international JIA prevalence data measurements $(0.07$ to $4.01 / 1000$ children $)^{32}$.

In adults with rheumatoid arthritis (RA), exposure to smoking is a consistently identified risk factor ${ }^{33}$. Because we had only $6 \%$ RF-positive JIA, we could not evaluate this 
Table 3. Exposure to cigarette smoke and inhaled pollutants after birth as risk factors for JIA in univariate, multilevel, and final multiple logistic regression models.

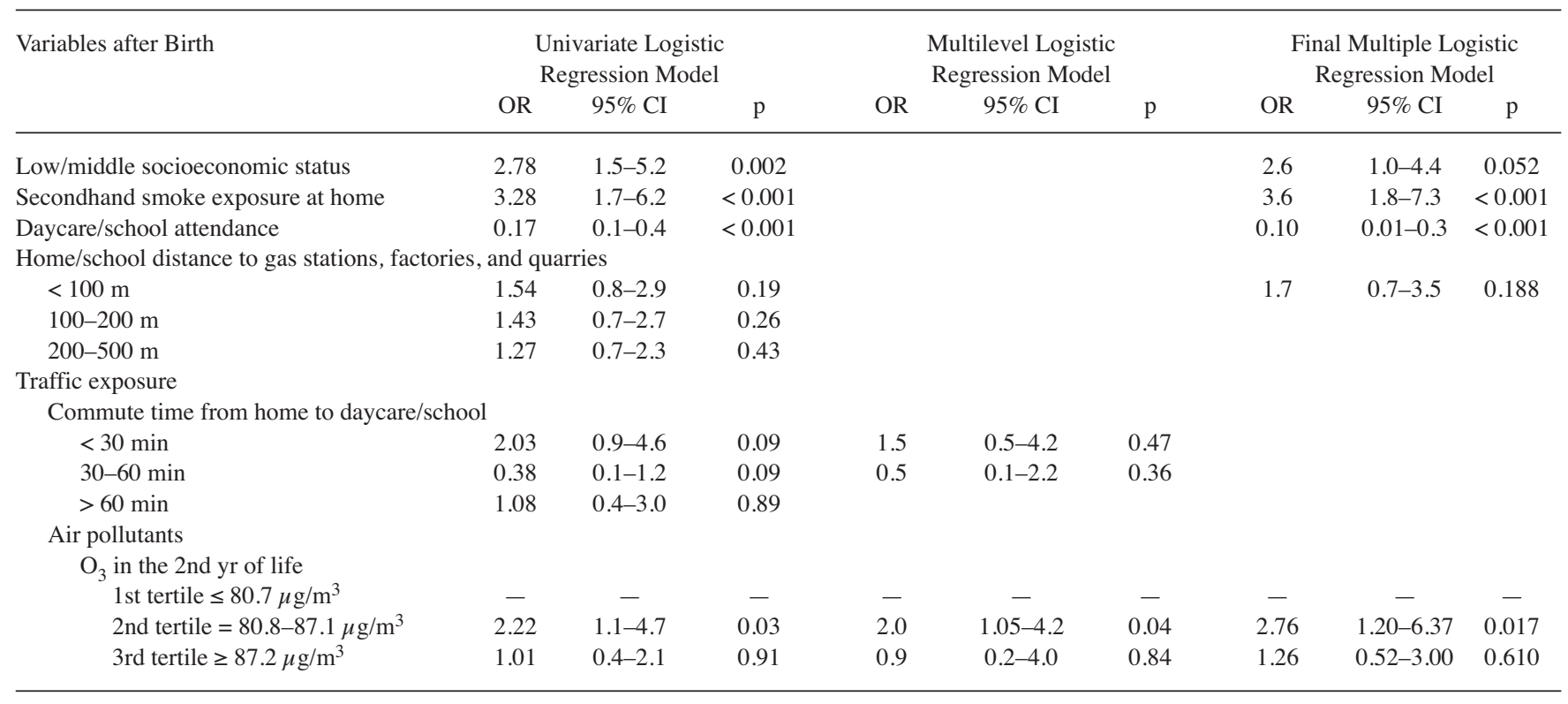

JIA: juvenile idiopathic arthritis; $\mathrm{O}_{3}$ : ozone.

Table 4. Exposure to cigarette smoke and inhaled pollutants in both periods (pregnancy, and from birth to JIA diagnosis) as risk factors for JIA for all patients and JIA categories.

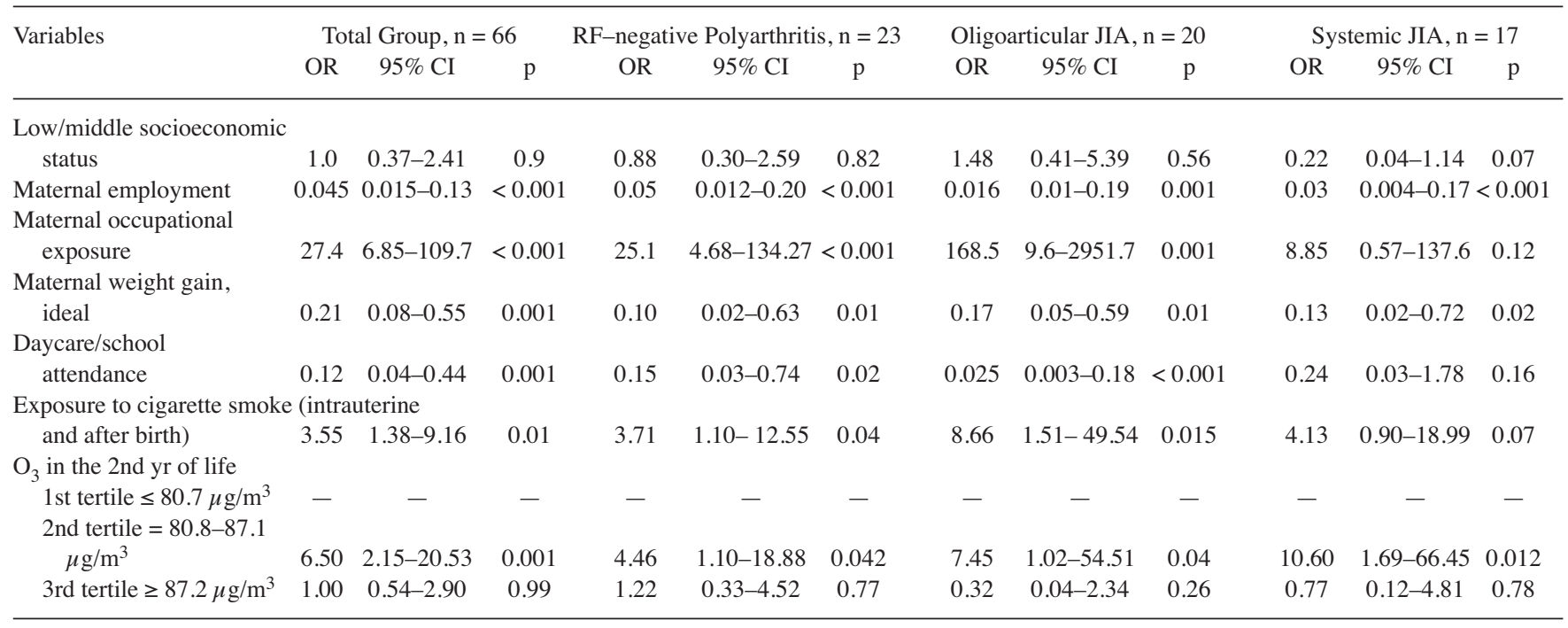

JIA: juvenile idiopathic arthritis; $\mathrm{O}_{3}$ : ozone.

category that most mimics adult RA for its cigarette smoke exposure or other exposures in our study.

Although there was a decrease in the number of smoking mothers during pregnancy in both the JIA and control groups, the smoking rate was higher in the JIA mothers during the year prior to pregnancy.

Mothers who smoke during pregnancy may have structural changes in the placenta, as well as decreased levels of placental methylation, and they may transfer to the fetus about 9600 chemicals present in tobacco, such as nicotine and $\operatorname{tar}^{34,35}$. Other studies have also shown an association between mothers who smoked during pregnancy and DNA methylation ${ }^{20,36,37,38}$. However, previous studies demonstrating an association between JIA onset and cigarette smoke exposure during pregnancy remain controversial ${ }^{22,23,24,39}$. In 2 studies, Shenoi, et al did not find evidence of an association between JIA and maternal prenatal smoking ${ }^{22,23}$; nevertheless, Jaakkola and Gissler found a higher positive associ- 
ation with chronic polyarthropathy in children with JIA whose mothers had smoked $>10$ cigarettes per day during pregnancy compared to nonsmoking mothers, although this effect was limited to girls ${ }^{24}$. Our results were almost similar to Jaakkola and Gissler's suggestion that exposure to cigarette smoke during pregnancy increases the risk of JIA in the long term. Further, our study evaluated exposure to cigarette smoke in both periods, during pregnancy and from birth to JIA diagnosis, and it was observed that longterm exposure to cigarette smoke was an important risk factor for all JIA categories studied. However, we did not observe an association between the number of cigarettes and JIA diagnosis. Further studies will be necessary to identify whether total duration or total dose is the most important risk factor.

Unexpectedly, we observed a negative association between maternal employment and JIA diagnosis during pregnancy. However, a positive association was observed among working mothers, in particular those exposed to chalk powder, cleaning products, sewing dust, and volatile vapor. Lower socioeconomic status might be associated with occupations in which exposure to environmental toxicants is higher. However, in our multivariate analysis, low/middle socioeconomic status was not associated with, and did not modify the positive association between, maternal occupational exposure and JIA diagnosis.

Maternal occupational exposure has not been previously studied in JIA. In addition, some studies observed a positive association between maternal occupational exposure and childhood chronic diseases, such as leukemia ${ }^{40,41}$, non-Hodgkin lymphoma ${ }^{40}$, and juvenile dermatomyositis ${ }^{17}$. It may thus be inferred, based on the literature and on our results, that working during pregnancy is not a matter of concern, but occupational exposure to inhalable toxic pollutants may play a role in JIA pathophysiology.

Moreover, we observed that ideal maternal weight gain during pregnancy was a protective factor for JIA. To our knowledge, this association had never been evaluated, and further studies are necessary to confirm this finding.

In our analysis regarding the period from birth to JIA diagnosis, the association with secondhand smoke exposure remained relevant. In RA, the association with smoking is well established ${ }^{32,42,43,44}$. Smoking and other inhalable proinflammatory agents may play a role in stimulating protein citrullination in the lungs, mediated by peptidylarginine deiminase enzymes, and may induce autoantibodies. In genetically predisposed individuals, protein citrullination affects the potential risk of anticitrullinated peptide autoantibody production ${ }^{34}$. These findings have not been studied among JIA populations, to our knowledge.

Studies evaluating the effects of exposure to tropospheric pollution on autoimmune inflammatory diseases have multiplied in the last decade, mainly with adults $2,3,11,13,14,15$. Outdoor air pollution studies on pediatric rheumatologic diseases are rare $e^{4,15,16,17,18,19}$.Zeft, et al found a high risk of
JIA development in children under 5 years associated with higher concentrations of $\mathrm{PM}_{2,5}$ and stagnant air conditions in the 14 days preceding JIA diagnosis ${ }^{16}$. This study is different from our study, which evaluated longterm exposure to tropospheric pollutants. Specifically, in the case of exposure to $\mathrm{O}_{3}$, there is sparse evidence of morbidity in longterm exposure cases. De Roos, et al demonstrated that longterm exposure to $\mathrm{O}_{3}$ was a risk factor for $\mathrm{RA}^{11}$. In our study, exposure to $\mathrm{O}_{3}$ in the second year of life represented a high risk for developing both overall and systemic JIA. Based on our results, we can speculate that exposure in the first 2 years of life to environmental toxicants that are proinflammatory may be a factor in the pathogenesis of JIA. One possible explanation for the extrapulmonary effects is the release of oxidative products into circulation originating from $\mathrm{O}_{3}$ effects on the lungs, leading to arterial endothelial damage. Damaged epithelial cells release other mediators into the blood that can activate a systemic inflammatory response ${ }^{45,46}$. The combination of damaged arterial endothelium and systemic inflammation can alter methylation at protein binding sites in DNA, leading to autoimmunity $47,48,49$.

Regarding the after-birth period, the only negative association with JIA development observed in our study was daycare/school attendance. Shenoi, et $a l^{23}$ also evaluated this characteristic and no association with JIA diagnosis was found. Hence, a negative association between the mother's employment and JIA diagnosis during pregnancy should be interpreted with caution, and more studies will be necessary.

Our study identified exposure to cigarette smoke either in utero or after birth as a risk factor associated with JIA. Our results are sufficiently compelling to warrant future studies to investigate the potential role of maternal occupational and air pollutant exposure in the pathogenesis of JIA.

\section{REFERENCES}

1. Stolt P, Kallberg H, Lundberg I, Sjogren B, Klareskog L, Alfredsson L; EIRA study group. Silica exposure is associated with increased risk of developing rheumatoid arthritis: results from the Swedish EIRA study. Ann Rheum Dis 2005;64:582-6.

2. Hart JE, Källberg H, Laden F, Bellander T, Costenbader KH, Holmqvist $\mathrm{M}$, et al. Ambient air pollution exposures and risk of rheumatoid arthritis: results from the Swedish EIRA case-control study. Ann Rheum Dis 2013;72:888-94.

3. Hart JE, Källberg H, Laden F, Costenbader KH, Yanosky JD, Klareskog L, et al. Ambient air pollution exposures and risk of rheumatoid arthritis. Arthritis Care Res 2013;65:1190-6.

4. Farhat SC, Silva CA, Orione MA, Campos LM, Sallum AM, Braga AL. Air pollution in autoimmune rheumatic diseases: a review. Autoimmun Rev 2011;11:14-21.

5. World Health Organization. Ambient air pollution: A global assessment of exposure and burden of disease 2016. [Internet: Accessed October 16, 2017.] Available from: who.int/phe/ publications/air-pollution-global-assessment/en

6. Perez-Padilla R, Schilmann A, Riojas-Rodriguez H. Respiratory health effects of indoor air pollution. Int J Tuberc Lung Dis 2010;14:1079-86.

7. Apte K, Salvi S. Household air pollution and its effects on health. F1000Res 2016;5:F1000 Faculty Rev-2593.

Personal non-commercial use only. The Journal of Rheumatology Copyright @ 2018. All rights reserved. 
8. Brook RD, Rajagopalan S, Pope CA 3rd, Brook JR, Bhatnagar A, Diez-Roux AV, et al. Particulate matter air pollution and cardiovascular disease: An update to the scientific statement from the American Heart Association. Circulation 2010;121:2331-78.

9. Elvidge T, Matthews IP, Gregory C, Hoogendoorn B. Feasibility of using biomarkers in blood serum as markers of effect following exposure of the lungs to particulate matter air pollution. J Environ Sci Health C Environ Carcinog Ecotoxicol Rev 2013;31:1-44.

10. Calderón-Garcidueñas L, Villareal-Calderon R, Valencia-Salazar G, Henriquez-Roldán C, Gutiérrez-Castrellón P, Torres-Jardón R, et al. Systemic inflammation, endothelial dysfunction, and activation in clinically healthy children exposed to air pollutants. Inhal Toxicol 2008;20:499-506.

11. De Roos AJ, Koehoorn M, Tamburic L, Davies HW, Brauer M. Proximity to traffic, ambient air pollution, and community noise in relation to incident rheumatoid arthritis. Environ Health Perspect 2014;122:1075-80.

12. Hart JE, Laden F, Puett RC, Costenbader KH, Karlson EW. Exposure to traffic pollution and increased risk of rheumatoid arthritis. Environ Health Perspect 2009;117:1065-9.

13. Chang KH, Hsu CC, Muo CH, Hsu CY, Liu HC, Kao CH, et al. Air pollution exposure increases the risk of rheumatoid arthritis: $\mathrm{A}$ longitudinal and nationwide study. Environ Int 2016;94:495-99.

14. Bernatsky S, Smargiassi A, Barnabe C, Svenson LW, Brand A, Martin RV, et al. Fine particulate air pollution and systemic autoimmune rheumatic disease in two Canadian provinces. Environ Res 2016;146:85-91.

15. Vidotto JP, Pereira LA, Braga AL, Silva CA, Sallum AM, Campos LM, et al. Atmospheric pollution: influence on hospital admissions in paediatric rheumatic diseases. Lupus 2012;21:526-33.

16. Zeft AS, Prahalad S, Lefevre S, Clifford B, McNally B, Bohnsack $\mathrm{JF}$, et al. Juvenile idiopathic arthritis and exposure to fine particulate air pollution. Clin Exp Rheumat 2009;27:877-84.

17. Orione MA, Silva CA, Sallum AM, Campos LM, Omori CH, Braga AL, et al. Risk factors for juvenile dermatomyositis: exposure to cigarette smoke and air pollutants during pregnancy. Arthritis Care Res 2014;76:1571-5.

18. Zeft AS, Prahalad S, Schneider R, Dedeoglu F, Weiss PF, Grom AA, et al. Systemic onset juvenile idiopathic arthritis and exposure to fine particulate air pollution. Clin Exp Rheumatol 2016;34:946-52.

19. Fernandes EC, Silva CA, Braga AL, Sallum AM, Campos LM, Farhat SC. Exposure to air pollutants increased disease activity in childhood-onset systemic lupus erythematosus patients. Arthritis Care Res 2015;67:1609-14.

20. Joubert BR, Håberg SE, Nilsen RM, Wang X, Vollset SE, Murphy SK, et al. 450K epigenome-wide scan identifies differential DNA methylation in newborns related to maternal smoking during pregnancy. Environ Health Perspect 2012;120:1425-31.

21. Knopik VS, Maccani MA, Francazio S, McGeary JE. The epigenetics of maternal cigarette smoking during pregnancy and effects on child development. Dev Psychopathol 2012;24:1377-90.

22. Shenoi S, Bell S, Wallace CA, Mueller BA. Juvenile idiopathic arthritis in relation to maternal prenatal smoking. Arthritis Care Res 2015;67:725-30.

23. Shenoi S, Shaffer ML, Wallace CA. Environmental risk factors and early-life exposures in juvenile idiopathic arthritis: a case-control study. Arthritis Care Res 2016;68:1186-94

24. Jaakkola JJ, Gissler M. Maternal smoking in pregnancy as a determinant of rheumatoid arthritis and other inflammatory polyarthropathies during the first 7 years of life. Int J Epidemiol 2005;34:664-71.

25. Petty RE, Southwood TR, Manners P, Baum J, Glass DN, Goldenberg $\mathrm{J}$, et al. International League of Associations for Rheumatology classification of juvenile idiopathic arthritis: second revision, Edmonton, 2001. J Rheumatol 2004;31:390-2.
26. ABEP. [Critério padrão de classificação econômica Brasil 2013]. [Web site in Portuguese. Accessed October 16, 2017]. Available from: www.abep.org/criterio-brasil

27. Guimarães MT, Cunha MG, Carvalho DP, Sampaio T, Braga AL, Pereira LA. [Pregnancy outcomes in contaminated areas, SP, Brazil]. [Article in English and Portuguese]. Rev Bras Epidemiol 2011;14:598-608

28. Centers for Disease Control and Prevention (CDC). Alcohol use and your health. [Internet. Accessed October 16, 2017]. Available from: www.cdc.gov/alcohol/fact-sheets/alcohol-use.htm

29. CETESB. [Redes de Monitoramento]. [Web site in Portuguese. Accessed October 16, 2017]. Available from: sistemasinter.cetesb.sp.gov.br/ar/ar_automatica.asp

30. The National Academies Press. Weight gain during pregnancy: reexamining the guidelines (2009). [Internet. Accessed October 16, 2017). Available from: www.nap.edu/search/?term=Weight+ Gain+During+Pregnancy\%3A+Reexamining+the+Guidelines

31. Silva CA, Silva CH, Robazzi TC, Lotito AP, Mendroni Junior A, Jacob CM, et al. [Macrophage activation syndrome associated with systemic juvenile idiopathic arthritis]. [Article in Portuguese] J Pediatr 2004;80:517-22.

32. Yamashita E, Terreri MT, Hilário MO, Len CA. Prevalence of juvenile idiopathic arthritis in children aged 6 to 12 years in Embu das Artes, state of São Paulo, Brazil. Rev Bras Reumatol 2013;53:542-5.

33. Afridi HI, Kazi TG, Talpur FN, Naher S, Brabazon D. Relationship between toxic metals exposure via cigarette smoking and rheumatoid arthritis. Clin Lab 2014;60:1735-45.

34. Anderson R, Meyer PW, Ally MM, Tikly M. Smoking and air pollution as pro-inflammatory triggers for the development of rheumatoid arthritis. Nicotine Tob Res 2016;18:1556-65.

35. Shea AK, Steiner M. Cigarette smoking during pregnancy. Nicotine Tob Res 2008; 10:267-78

36. Breton CV, Siegmund KD, Joubert BR, Wang X, Qui W, Carey V, et al. Prenatal cigarette smoke exposure is associated with childhood DNA CpG methylation. PLoS One 2014;9:e99716.

37. Lee KW, Richmond R, Hu P, French L, Shin J, Bourdon C, et al. Prenatal exposure to maternal cigarette smoking and DNA methylation: epigenome-wide association in a discovery sample of adolescents and replication in an independent cohort at birth through 17 years of age. Environ Health Perspect 2015;123:193-9.

38. Morales E, Vilahur N, Salas LA, Motta V, Fernandez MF, Murcia $\mathrm{M}$, et al. Genome-wide DNA methylation study in human placenta identifies novel loci associated with maternal smoking during pregnancy. Int J Epidemiol 2016;45:1644-55.

39. Ellis JA, Ponsonby AL, Pezic A, Chavez RA, Allen RC, Akikusa JD, et al. CLARITY: childhood arthritis risk factor identification study. Pediatr Rheumatol Online J 2012;10:37.

40. Miligi L, Benvenuti A, Mattioli S, Salvan A, Tozzi GA, Ranucci A, et al. Risk of childhood leukaemia and non-Hodgkin's lymphoma after parental occupational exposure to solvents and other agents: the SETIL Study. Occup Environ Med 2013;70:648-55.

41. Zhou Y, Zhang S, Li Z, Zhu J, Bi Y, Bai Y, et al. Maternal benzene exposure during pregnancy and risk of childhood acute lymphoblastic leukemia: a meta-analysis of epidemiologic studies. PLoS One 2014;9:e110466.

42. Di Giuseppe D, Discacciati A, Orsini N, Wolk A. Cigarette smoking and risk of rheumatoid arthritis: a dose-response meta-analysis. Arthritis Res Ther 2014;16:R61.

43. Sugiyama D, Nishimura K, Tamaki K, Tsuji G, Nakazawa T, Morinobu A, et al. Impact of smoking as a risk factor for developing rheumatoid arthritis: a meta-analysis of observational studies. Ann Rheum Dis 2010;69:70-81.

44. Karlson EW, Lee IM, Cook NR, Manson JE, Buring JE, Hennekens $\mathrm{CH}$. A retrospective cohort study of cigarette smoking and risk of 
rheumatoid arthritis in female health professionals. Arthritis Rheum 1999;42:910-7.

45. Chuang GC, Yang Z, Westbrook DG, Pompilius M, Ballinger CA, White CR, et al. Pulmonary ozone exposure induces vascular dysfunction, mitochondrial damage, and atherogenesis. Am J Physiol Lung Cell Mol Physiol 2009;297:L209-16.

46. Goodman JE, Prueitt RL, Sax SN, Pizzurro DM, Lynch HN, Zu K. Ozone exposure and systemic biomarkers: Evaluation of evidence for adverse cardiovascular health impacts. Critical Rev Toxicol 2015;45:412-52.

47. Farhat J, Farhat SC, Braga AL, Cocuzza M, Borba EF, Bonfá E, et al. Ozone decreases sperm quality in systemic lupus erythematosus patients. Rev Bras Reumatol Engl Ed 2016;56:212-9.

48. Gryparis A, Forsberg B, Katsouyanni K, Analitis A, Touloumi G, Schwartz J, et al. Acute effects of ozone on mortality from the air pollution and health: a European approach project. Am J Respir Crit Care Med 2004;170:1080-7.

49. Watkinson WP, Campen MJ, Nolan JP, Costa DL. Cardiovascular and systemic responses to inhaled pollutants in rodents: effects of ozone and particulate matter. Environ Health Perspect 2001;109 Suppl 4:539-46. 